\title{
Established paths and new avenues: a review of the main radiological techniques for investigating sarcopenia
}

\author{
Chiara Giraudo ${ }^{1}$, Annachiara Cavaliere ${ }^{1}$, Amalia Lupi ${ }^{1}$, Giuseppe Guglielmi ${ }^{2}$, Emilio Quaia ${ }^{1}$ \\ ${ }^{1}$ Radiology Institute, Department of Medicine-DIMED, University of Padova, Padova, Italy; ${ }^{2}$ Department of Radiology, Scientific Institute "Casa \\ Sollievo della Sofferenza" Hospital, University of Foggia, Foggia, Italy
}

Correspondence to: Emilio Quaia, MD, PhD. Full Professor of Radiology, Radiology Institute, Department of Medicine-DIMED, University of Padova, Via Giustiniani 2, 35100 Padova, Italy. Email: emilio.quaia@unipd.it.

\begin{abstract}
Sarcopenia is a clinical condition mainly affecting the elderly that can be associated in a long run with severe consequences like malnutrition and frailty. Considering the progressive ageing of the world population and the socio-economic impact of this disease, much effort is devoted and has to be further focused on an early and accurate diagnostic assessment of muscle loss. Currently, several radiological techniques can be applied for evaluating sarcopenia. If dual-energy X-ray absorptiometry (DXA) is still considered the main tool and it is even recommended as reference by the most current guidelines of the European working group on sarcopenia in older people (EWGSOP), the role of ultrasound (US), computed tomography (CT), peripheral quantitative CT (pQCT), and magnetic resonance imaging (MRI) should not be overlooked. Indeed, such techniques can provide robust qualitative and quantitative information. In particular, regarding MRI, the use of sequences like diffusion-weighted imaging (DWI), diffusion tensor imaging (DTI), magnetic resonance spectroscopy (MRS) and mapping that could provide further insights into the physiopathological features of sarcopenia, should be fostered. In an era pointing to the quantification and automatic evaluation of diseases, we call for future research extending the application of organ tailored protocols, taking advantage of the most recent technical developments.
\end{abstract}

Keywords: Sarcopenia; radiology; absorptiometry; computed tomography (CT); magnetic resonance (MR)

Submitted Oct 15, 2019. Accepted for publication Dec 19, 2019.

doi: 10.21037 /qims.2019.12.15

View this article at: http://dx.doi.org/10.21037/qims.2019.12.15

\section{Introduction}

Since the first definition of sarcopenia made by Rosenberg et al. in 1989, who described it as a progressive muscle loss related to aging, much effort has been devoted by the scientific community to better characterize this condition that now is even recognized by a specific code according to the international classification of diseases (ICD-10) (1-3). In particular, in 2010, the European working group on sarcopenia in older people (EWGSOP) encouraged diagnosis and care for patients with sarcopenia (4). The same group released in 2018 an updated consensus paper with a strong focus on qualitative and quantitative features of muscle loss and proposing a revised diagnostic algorithm (5).
In addition to the recommendations of specific working groups, the increasing literature of the last decade about this disease underlines the global attention on this condition. The high consideration that sarcopenia is receiving is surely linked to the progressively aging of the world population and to the severe consequences accompanying muscle loss $(6,7)$.

Concerning the aging process, in 2019, the World Health Organization (WHO) estimated that the number of people older than 60 years will grow by $56 \%$ in 2030, from 962 million to 1.4 billion (8). Already in 2018, the WHO addressed the importance of muscle mass as key element for the well-being of the elderly. Indeed, an adequate muscle mass is considered essential to preserve cognitive functioning, delay care dependency, and reverse frailty (8). 
In particular, prospective studies demonstrated how muscle loss is associated with adverse outcomes including falls, disability, and incidents. It may also start a vicious cycle, amplified by the aging process, in which the loss of power causes difficulties in procuring adequate nutrition and progressively reduces independence (6). Lastly, it was recently highlighted that even cognitive impairment and depression can be associated with sarcopenia $(7,9,10)$.

The severe socio-economic impact of all these aspects cannot be underestimated. Thus, the scientific community has issued a call to action not only for tailored treatments and social support for patients with sarcopenia but also for an accurate and early diagnostic assessment.

In the diagnostic evaluation of sarcopenia, radiological imaging plays a key role and several techniques can be used. Dual-energy X-ray absorptiometry (DXA), based on the different absorption of low and high energy $\mathrm{X}$-rays by the different body components, has initially been applied to measure bone mineral density but is now increasingly used for muscles evaluation (11-14). The importance of this technique is also demonstrated by the fact that it is recommended for clinical assessment by the last consensus paper of the EWGSOP (5).

Computed tomography (CT) and peripheral quantitative CT (pQCT) which are based on the attenuation of X-rays have a consolidated role for this condition, allowing also quantitative analyses (15-20).

The diagnostic value of techniques not associated with ionizing radiation and especially suitable for the evaluation of soft tissues like ultrasound (US) and magnetic resonance (MR) has been widely evaluated demonstrating good results. Nevertheless, according to the current guidelines, the latter method is still recommended mainly for research $(5,21-23)$.

Thus, considering the importance of sarcopenia and the fundamental role of radiological imaging, aim of this review is to provide a comprehensive overview of the advantages and disadvantages of the main different imaging modalities useful for investigating muscle loss, including insights into specific techniques, such as diffusion-weighted imaging (DWI), diffusion tensor imaging (DTI), magnetic resonance spectroscopy (MRS) and mapping.

\section{Radiological techniques}

\section{$D X A$}

DXA provides a model of body composition including fat, bone mineral density and lean mass (12). As above- mentioned, in the last consensus paper, the EWGSOP indicated DXA as the method of choice in clinical practice for the assessment of muscle mass, highlighting its good correlation with the measurements obtained by CT and $\operatorname{MR}(5,24)$.

Since the entire body mass influences muscle tissues, the absolute DXA measurements have to be adjusted according to the overall body surface (i.e., height squared, weight or body mass index) (25). In particular, the appendicular lean mass index provides clinically relevant information because the appendicular skeletal muscle mass is critical to preserve mobility and functional independence in the elderly $(24,26)$.

Among the numerous advantages of DXA, it should be listed that it provides reliable measurements without being invasive, allows fast analyses, and it is highly reproducible when the same device and fixed thresholds are used. Unfortunately, the reliability of this technique decreases when different devices are applied. It should also be considered that factors like the level of hydration of the patients may influence the results (5). Lastly, it should be addressed that the position statements of the Sarcopenia Definition and Outcomes Consortium released in 2019 highlight that the measurement of the appendicular lean mass obtained by DXA is not seen as a good predictor of adverse outcomes in the elderly $(27,28)$.

\section{$C T$}

CT can be considered overall the gold standard for the assessment of body composition since it allows a distinction of different tissues according to the attenuation of the $\mathrm{X}$-ray beam. Referring to the Hounsfield Unit (HU), the standard unit of measurement, muscles with values ranging from -29 to +29 are considered low attenuating (29-31). CT allows the analysis of fat distribution within muscles, distinguishing between fat around the muscle and interstitial adipose tissue, thus providing a qualitative and quantitative characterization $(18,32)$.

The quantification of muscle mass is usually performed segmenting definite muscle groups, whose crosssectional area correlates with the whole-body muscle mass (Figure 1). Even if one of the most frequent level for the measurements is represented by the third lumbar vertebra, when abdominal CT scans are available, other muscles, for instance at the thoracic or cervical level, have been used in the literature with good results (33-37).

For instance, Nemec and colleagues diagnosed sarcopenia, using the muscles at the T12 level, in patients 

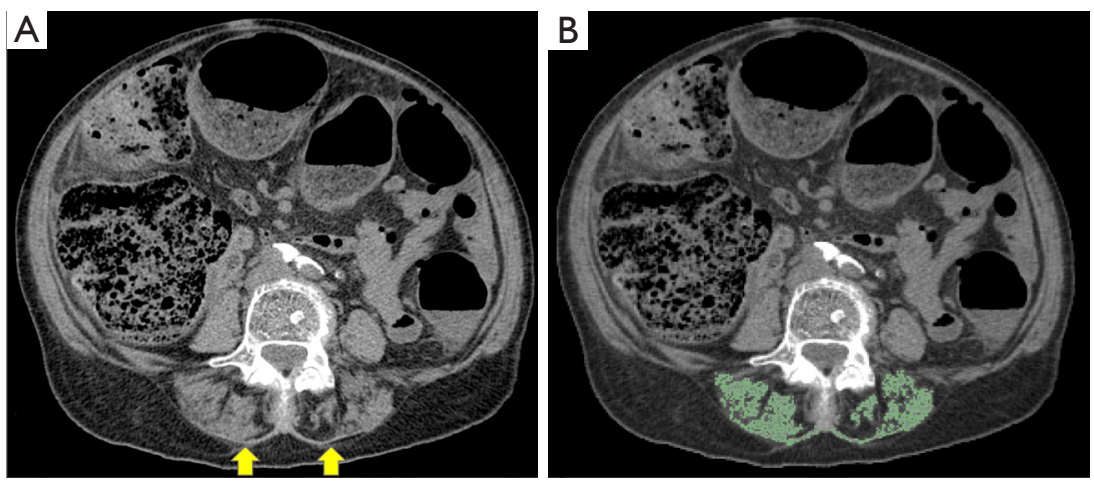

Figure 1 Axial CT scan of an 87-year-old female patient affected by cirrhosis and acute large bowel obstruction with signs of paravertebral muscles loss at level of L3 (yellow arrows in A). CT-based quantification of the muscle mass of the same patient using an open source software in (B) (3D slicer, www.slicer.org). CT, computed tomography.

that underwent transcatheter aortic valve replacement and found a correlation between the skeletal muscle index and the length of stay (36). Similarly, Nattenmüller et al., demonstrated how patients with lung cancer are affected by sarcopenia after chemotherapy and that it had a negative impact on the adherence to the treatment and to the overall survival (38).

It has to be highlighted that up to now, most of the studies were based on manual segmentations which are time consuming and affected by interobserver variability. Recently this drawback has been partially overcome by semi- or fully automated segmentation models that are providing promising results (15-17).

\section{$p Q C T$}

pQCT, originally designed to assess structural properties like bone density and mineral content of the limbs, has been also successfully applied to investigate muscle loss (39). Indeed, muscle cross-sectional area, muscle density and intramuscular adipose tissue area can be evaluated on a single slice of interest using dedicated software distinguishing all the components (i.e., fat, muscles, and bones) by the selection of density thresholds (39).

Using pQCT, it has been demonstrated that the measurement of the muscle cross sectional area correlates with those obtained by MRI and that, in adults, smaller areas and muscles with lower density are associated with high mortality $(19,20)$.

In comparison to conventional CT, pQCT carries the advantages of lower radiation doses and reduced costs (39). Nevertheless, its clinical application is still hampered by the lack of standardization in the protocols for the acquisition and analyses of the datasets. Moreover, specific recommendations regarding the site of measurement are still missing, even if the radius and the tibia are mainly examined (39).

\section{US}

Allowing a precise investigation of soft tissues, US has been successfully applied also for patients with sarcopenia (22). In addition to the qualitative assessment, which is characterized by a higher echogenicity in case of fibro-fatty infiltration, quantitative parameters like muscle thickness, cross-sectional area, fiber length, and pennation angle can be measured (Figure 2) $(21,22)$. For instance, Ismail et al. demonstrated that US morphometry values are associated with lean body mass allowing the discrimination between women with and without sarcopenia (40).

While US shows certain intrinsic advantages (e.g., costeffectiveness and the absence of ionizing radiation), that make it especially suitable for repeated measurements and to investigate pediatric patients, there are some drawbacks which cannot be overlooked. Indeed, it is highly dependent on the expertise and skills of the operator (41). Furthermore, it does not provide a comprehensive overview of the body and up to now a standardized approach regarding the best and most representative sites where to target the assessment in patients with sarcopenia are not available. In fact, muscles investigated by US might not be representative of the whole-body mass since muscle loss may not affect all compartments simultaneously or with the same severity $(21,42,43)$. 


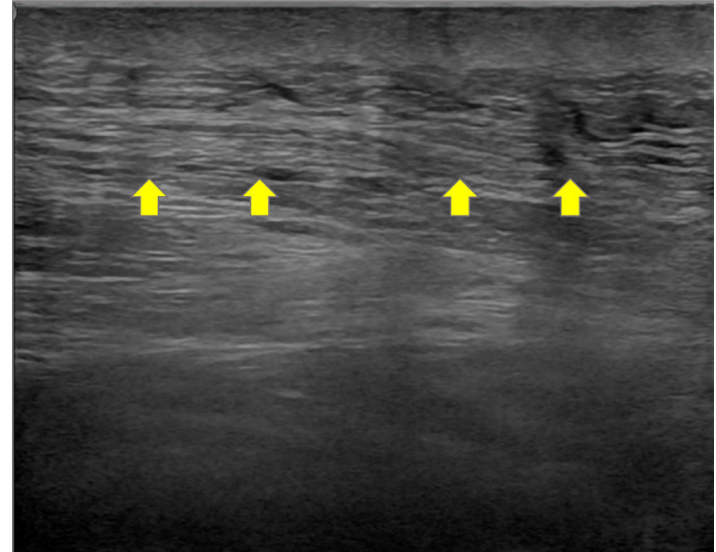

Figure 2 US scan of the left gluteus muscle of a 72-year-old male patient, referring loss of muscle strength, showing high echogenicity of the muscle tissue (yellow arrows). US, ultrasound.

\section{MRI}

MRI is widely considered as one of the most adequate and reliable techniques to investigate muscles because of its intrinsic high soft tissue contrast. Moreover, the continuous technical progress associated with the development of new sequences and tools allows a constantly increasing accuracy in assessing pathological changes affecting this tissue. The estimation of muscles' degenerative processes routinely performed by semi-quantitative scores (e.g., Goutallier classification and Mercuri score) on T1weighted turbo spin-echo images, can be implemented by robust quantitative analyses able to reveal even subclinical progressions (Figure 3) $(23,44,45)$.

Indeed, currently, not only a qualitative evaluation of features like edema and fatty replacement can be performed but techniques like Dixon, DWI, DTI and mapping can be used to collect accurate quantitative data.

\section{Chemical-shift based imaging}

Chemical shift-based water/fat separation imaging and two-/multi-point Dixon sequences are often the modalities of choice to evaluate muscle fat fraction, also in clinical settings $(46,47)$. These techniques rely on the different resonance frequency of fat and water protons, which permits the differentiation and quantification of the fat fraction through slight adjustments of the echo time. In particular, Dixon allows "fat-only" and "water-only" images through the acquisition of two or more echoes at different echo times (Figure 4) $(24,47)$. This technique, allowing the separation of "healthy" muscles with preserved contractile properties from fat-containing, un-contractile fibers, gives detailed information about the functional mass $(46,48)$.

In in-vivo and phantom-based studies, Dixon showed high accuracy for the assessment of fatty replacement of muscles in dystrophic patients $(49,50)$. Moreover, it has been successfully applied for evaluating muscle atrophy, adipose infiltration and interstitial fibrosis of denervated skeletal muscle due to traumatic injuries of the brachial plexus $(46,48)$.

Adipose infiltration was accurately assessed also in patients with rotator cuff tears (51) and diabetes mellitus (52).

In addition to its quantitative properties, Dixon demonstrated a good performance in comparison to short tau inversion recovery (STIR) and/or chemical fat suppression sequences for diagnosing muscle edema occurring in early denervation stages (46).

The technical improvements of the last decade, including significant developments of new algorithms [e.g., iterative decomposition of water and fat with echo asymmetry and least-squares estimation (IDEAL)] further promoted the use of Dixon imaging (53). Despite all the advantages, some limitations may hamper the application of this sequence. For instance, it requires long acquisition time and is prone to artifacts in case of metal protheses. The recent threepoint Dixon allowed to overcome the sensitivity to B0 inhomogeneities that was causing "fat-water swapping artifacts", due to phase shift errors, typical of two-point Dixon imaging (54).

\section{MRS}

MRS is a non-invasive technique allowing a characterization of the biochemical composition of tissues by separating different metabolites according to their unique chemical shift properties (55).

The first musculoskeletal applications of MRS were focused on the analyses of phosphorus-containing $\left({ }^{31} \mathrm{P}\right)$ compounds in muscles (56). Indeed, ${ }^{31} \mathrm{P}$ is a component of adenosine triphosphate, phosphocreatine, and inorganic phosphate, all molecules involved in the metabolic processes of muscle fibers. Thus, ${ }^{31} \mathrm{P}$-MRS has been used to assess patterns of catabolic processes and exercise-related changes (56-60).

Numerous studies on both animal models and humans, applying ${ }^{31} \mathrm{P}-\mathrm{MRS}$, identified metabolic profiles characterizing muscle degeneration and regeneration in specific diseases like Duchenne, and facio-scapulo-humeral muscular dystrophy $(46,61,62)$. In particular, it has been shown that in the latter disease, the concentration of ${ }^{31} \mathrm{P}$ 

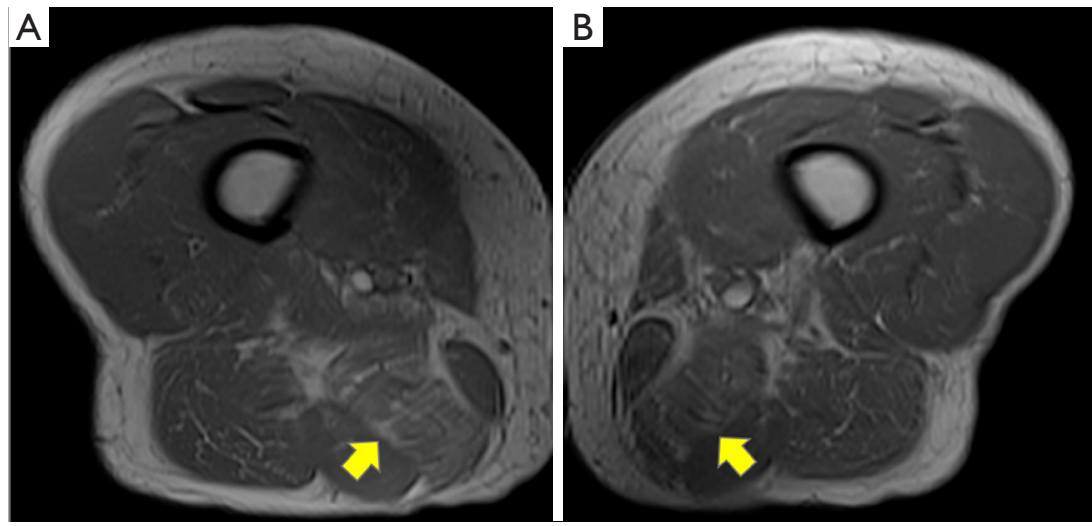

Figure 3 T1-weighted axial turbo spin echo of a 64-year-old male patient with chronic pulmonary disease well demonstrating muscle atrophy especially affecting the semimembranosus muscle on both sides (yellow arrows).
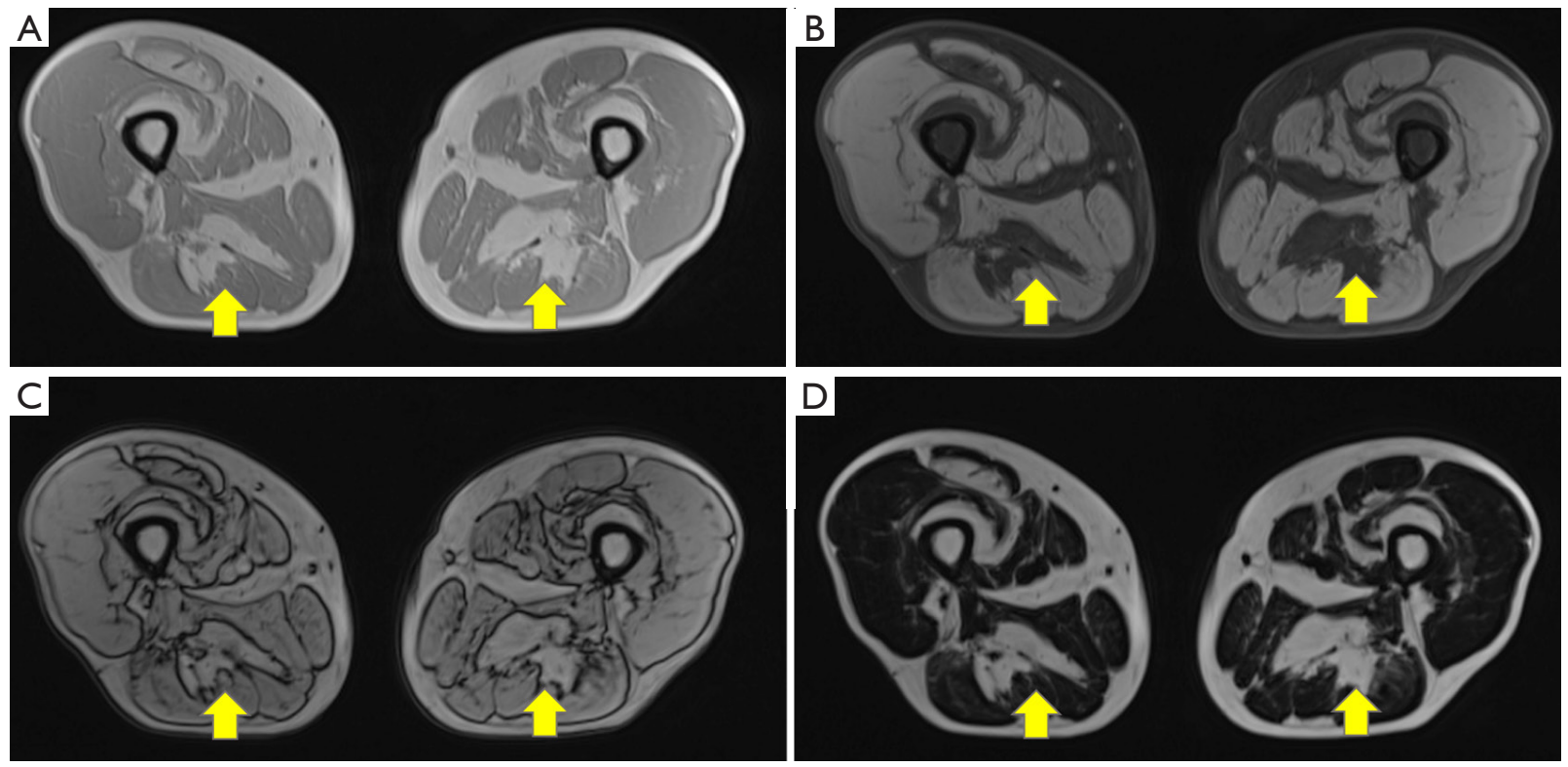

Figure 4 Axial in-phase (A), water-only (B), out of phase (C), and fat-only (D) Dixon images of a 64-year-old male patient with severe myositis, well demonstrating diffuse severe fatty conversion of the muscles of both thighs more severe in the posterior compartment (yellow arrows).

correlates with the extent and rate of fat replacement and muscle strength $(46,62)$.

Unfortunately, the routine clinical application of ${ }^{31} \mathrm{P}-\mathrm{MRS}$ is hampered by the low sensitivity of ${ }^{31} \mathrm{P}(63)$. In fact, to obtain adequate signal-to-noise ratio of phosphate metabolites, which have a very low concentration, long acquisition times are needed (63).

On the contrary, in vivo proton MRS ( $\left.{ }^{1} \mathrm{H}-\mathrm{MRS}\right)$ allows the assessment of intra and extramyocellular lipids on clinical MR devices (55). This was well demonstrated for instance by Torriani et al. in their ${ }^{1} \mathrm{H}-\mathrm{MRS}$ study showing how the amount of intramyocellular lipids is linked to reduced insulin sensitivity in healthy, obese or type 2 diabetic patients (64).

Investigating patients with myositis, it has even been suggested that changes in ${ }^{1} \mathrm{H}-\mathrm{MRS}$ profiles may precede pathologic changes on anatomical MRI. Indeed, using this technique, Subhawong et al. showed that creatine 

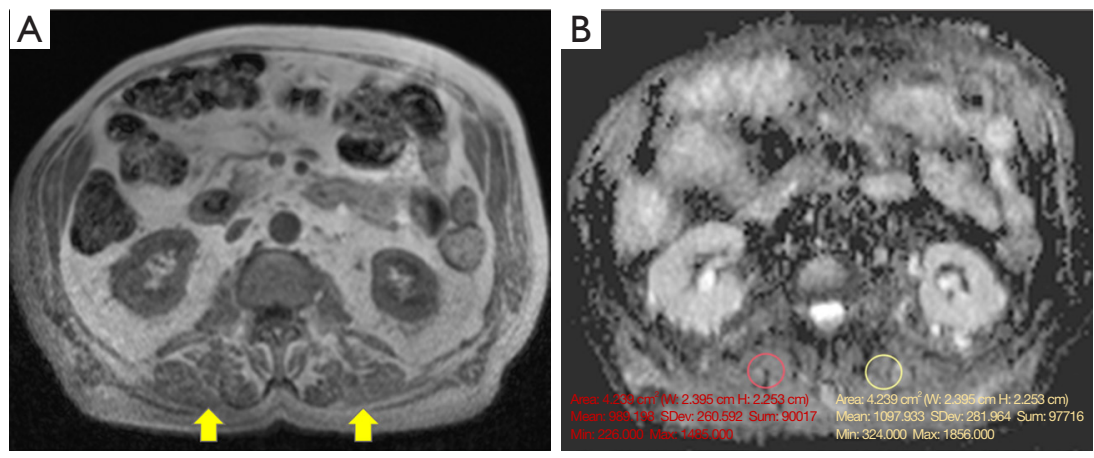

Figure 5 Axial T1-weighted turbo spin echo (A) and ADC map (B) of a 79-year-old male patient with metastatic colon cancer affected also by moderate atrophy of the paravertebral muscles at the L3 level (yellow arrows), especially on the left side. In agreement with the recent literature, which even proposed ADC values as biomarker of sarcopenia (70,71), in our patient, the left paravertebral muscles, which were more affected by atrophic changes, showed higher ADC values (red and yellow circles in B). ADC, apparent diffusion coefficient.

concentration is higher in apparently normal muscles (i.e., on T1-weighted and STIR sequences) of patients affected by myositis than in healthy controls (65). This finding might be applied to identify diseases at an early stagediseases, when they theoretically could still be reversible.

Recently, comparing Dixon and ${ }^{1} \mathrm{H}-\mathrm{MRS}$ similar levels of accuracy and repeatability in assessing the fat fraction have been demonstrated $(24,49)$. It has to be highlighted that ${ }^{1} \mathrm{H}-\mathrm{MRS}$ has the capability of distinguishing between intramyocellular and extramyocellular lipid components whereas Dixon maps of the fat fraction distribution can be especially useful for "patchy" physio-pathological processes such as fibro-fatty replacement areas.

It should be also considered that recent technical improvements allow the examination of multiple voxels during a single acquisition. Previous protocols based on single-voxel spectroscopy were somehow affected by the same bias of muscle biopsies, providing a limited representation of the investigated disease due to sampling only of small muscle areas. The development of fast MRS techniques such as multiple-echo acquisition, echo-planar spectroscopy imaging, and parallel encoded MRS has reduced the scan time and allowed the efficient acquisition of spectra over large regions $(46,66)$. Therefore, we may expect a progressively increasing application of MRS for muscle diseases, including sarcopenia.

\section{DWI}

DWI is a technique based on the degree of motion of water molecules in tissues that is related to their interaction with cell membranes and macromolecules $(67,68)$. Aside from brain imaging, DWI's main field of application is oncological imaging (69-71). However, it can be also reliably used for musculoskeletal diseases including myositis and sarcopenia (46,72-74). Indeed, in muscles, extra-, intra-, and transcellular water diffusion as well as capillary perfusion occur and the signal attenuation on DWI images is mainly due to the extracellular component and to microvascular perfusion (75).

Regarding the application of DWI for sarcopenia, Surov et al. found a significant correlation between the model for end stage-liver disease and muscle changes in patients with cirrhosis, and even proposed the apparent diffusion coefficient (ADC) as new biomarker (74). Similarly, McPherson and colleagues identified significant differences in $\mathrm{ADC}$ values of the lower limb muscles between patients with spinal cord injury and healthy controls (75) (Figure 5).

Despite its numerous advantages, DWI is affected by several limitations and technical challenges that should be taken into account, like, for instance, long acquisition times, high sensitivity to field inhomogeneities, and the necessity of strong gradients (76).

\section{DTI}

Muscles have a highly ordered structure that is especially suitable for being investigated by DTI. Indeed, the diffusion tensor is a $3 \mathrm{D}$ way of modeling DWI datasets with three principal diffusivities and as many directions. This technique allows an indirect assessment of tissues' anisotropy and structural orientation (77-79) which are expressed by variables like fractional anisotropy (FA), mean (MD), radial, and axial diffusivity. 
Initially, most of the musculoskeletal studies applying DTI were focused on the feasibility and reproducibility of the analyses as well as on the assessment of characteristics like fiber length, pennation angles, fiber curvature (80-83). Recently, DTI has been successfully applied for muscle diseases, including sarcopenia, and injuries (84-86).

For instance, Esposito et al., using an animal model, demonstrated that, responding to muscle injury and adapting to aging, muscles show an increase in FA (87). It has also been shown, in healthy volunteers, that DTI is sensitive to age-related changes affecting the muscles of the lower limb (88). Furthermore, Ponrartana et al. found a significant correlation of MD and FA with age and muscle strength in pediatric patients affected by Duchenne dystrophy (89).

Although DTI gives new insights into muscle anatomy and diseases, several challenges and shortcomings are associated with this technique. Indeed, to achieve an accurate sensitivity for fiber anisotropy in muscles, long diffusion times are needed $(90,91)$. It has been demonstrated that stimulated echo acquisition mode (STEAM) sequences, which can be adjusted for long diffusion times represent a good solution (91). Nevertheless, it should not be overlooked that, since random areas of signal loss, probably due to involuntary muscle contractions, may occur with STEAM-DTI, using this sequence, a post-processing correction of such artifacts is recommended (92-95).

\section{T1 and T2 mapping sequences}

Following the good results obtained in cardiac imaging, T1 and T2 mapping have been applied also in the musculoskeletal field providing information about the changes occurring in the entire examined muscles and not just in targeted areas.

For instance, Marty et al. using a fast, dedicated T1 mapping sequence on healthy volunteers and patients with Becker muscle dystrophy, demonstrated that $T 1$ values can represent biomarker of fatty infiltrations and that they correlate with the measurements (i.e., fat fraction) obtained by Dixon (96).

Similarly, the T2 mapping provided promising results for evaluating not only inflammatory alterations, occurring for example in neuromuscular diseases and juvenile dermatomyositis, but also muscle changes due to aging (97-100). Indeed, Azzabou et al. demonstrated that the increase of water T2 might be due to changes in the type of fibers, while $\mathrm{T} 2$ heterogeneity might be associated with muscles disorganization caused, for instance, by fibrotic replacement (98).

As all techniques, also T1 and T2 mapping are affected by certain weaknesses. For example, in the global assessment of muscles, the different components of water and fat are not separated. To overcome this limitation, recently, the use of sequences based on MR fingerprinting has been proposed $(97,100)$.

\section{Conclusions}

In conclusion, several radiological techniques can be used for a reliable assessment of sarcopenia. Even if according to the last consensus paper of the EWGSOP, DXA still plays a pivotal role in clinical practice and CT and MR are mainly recommended for research, in an era pointing to the quantification and automatic evaluation of diseases, we call for future research extending the use of organ tailored protocols taking advantage of all the most recent technical developments. In particular, the use of MR sequences like DTI, MRS and mapping that could provide further insights into the physiopathological features of sarcopenia should be fostered. These techniques could potentially influence the global clinical management of such patients and contribute to the establishment of new standardized diagnostic criteria.

\section{Acknowledgments}

Funding: None.

\section{Footnote}

Provenance and Peer Review: With the arrangement by the Guest Editors and the editorial office, this article has been reviewed by external peers.

Conflicts of Interest: All authors have completed the ICMJE uniform disclosure form (available at http://dx.doi. org/10.21037/qims.2019.12.15). GG served as the unpaid Guest Editor of the special issue and serves as an unpaid editorial board member of Quantitative Imaging in Medicine and Surgery. The authors have no other conflicts of interest to declare.

Open Access Statement: This is an Open Access article distributed in accordance with the Creative Commons Attribution-NonCommercial-NoDerivs 4.0 International License (CC BY-NC-ND 4.0), which permits the noncommercial replication and distribution of the article with 
the strict proviso that no changes or edits are made and the original work is properly cited (including links to both the formal publication through the relevant DOI and the license). See: https://creativecommons.org/licenses/by-nc-nd/4.0/.

\section{References}

1. Rosenberg IH. Sarcopenia: origins and clinical relevance. J Nutr 1997;127:990S-1S.

2. Vellas B, Fielding RA, Bens C, Bernabei R, Cawthon PM, Cederholm T, Cruz-Jentoft AJ, Del Signore S, Donahue S, Morley J, Pahor M, Reginster JY, Rodriguez Mañas L, Rolland Y, Roubenoff R, Sinclair A, Cesari M. Implications of ICD-10 for sarcopenia clinical practice and clinical trials: report by the International Conference on Frailty and Sarcopenia Research Task Force. J Frailty Aging 2018;7:2-9.

3. 2018 ICD-10-CM Diagnosis Code M62.84. Available online: https://www.icd10data.com/ICD10CM/Codes/ M00-M99/M60-M63/M62-/M62.84

4. Cruz-Jentoft AJ, Baeyens JP, Bauer JM, Boirie Y, Cederholm T, Landi F, Martin FC, Michel JP, Rolland Y, Schneider SM, Topinková E, Vandewoude M, Zamboni M; European Working Group on Sarcopenia in Older People. Sarcopenia: European consensus on definition and diagnosis: report of the European Working Group on Sarcopenia in Older People. Age Ageing 2010;39:412-23.

5. Cruz-Jentoft AJ, Bahat G, Bauer J, Boirie Y, Bruyère O, Cederholm T, Cooper C, Landi F, Rolland Y, Sayer AA, Schneider SM, Sieber CC, Topinkova E, Vandewoude M, Visser M, Zamboni M; Writing Group for the European Working Group on Sarcopenia in Older People 2 (EWGSOP2), and the Extended Group for EWGSOP2. Sarcopenia: revised European consensus on definition and diagnosis. Age Ageing 2019;48:16-31. Erratum in: Age Ageing 2019;48:601.

6. Lang T, Streeper T, Cawthon P, Baldwin K, Taaffe DR, Harris TB. Sarcopenia: etiology, clinical consequences, intervention, and assessment. Osteoporos Int 2010;21:543-59.

7. Lee I, Cho J, Hong H, Jin Y, Kim D, Kang H. Sarcopenia is associated with cognitive impairment and depression in elderly Korean women. Iran J Public Health 2018;47:327-34.

8. World Health Organization. Decade Of Healthy Aging 2020-2030. Available online: https://www.who.int/docs/ default-source/documents/decade-of-health-ageing/ decade-ageing-proposal-en.pdf?sfvrsn=b0a7b5b1_12

9. Chang KV, Hsu TH, Wu WT, Huang KC, Han DS.
Association between sarcopenia and cognitive impairment: a systematic review and meta-analysis. J Am Med Dir Assoc 2016;17:1164.e7-15.

10. Kim M, Won CW. Sarcopenia is associated with cognitive impairment mainly due to slow gait speed: results from the Korean Frailty and Aging Cohort Study (KFACS). Int J Environ Res Public Health 2019;16:1-18.

11. Lorente Ramos RM, Azpeitia Armán J, Arévalo Galeano N, Muñoz Hernández A, García Gómez JM, Gredilla Molinero J. Dual energy X-ray absorptimetry: fundamentals, methodology, and clinical applications. Radiologia 2012;54:410-23.

12. Rubbieri G, Mossello E, Di Bari M. Techniques for the diagnosis of sarcopenia. Clin Cases Miner Bone Metab 2014;11:181-4.

13. Guglielmi G, Ponti F, Agostini M, Amadori M, Battista G, Bazzocchi A. The role of DXA in sarcopenia. Aging Clin Exp Res 2016;28:1047-60.

14. Carnevale V, Castriotta V, Piscitelli PA, Nieddu L, Mattera M, Guglielmi G, Scillitani A. Assessment of skeletal muscle mass in older people: comparison between 2 anthropometry-based methods and dual-energy X-ray absorptiometry. J Am Med Dir Assoc 2018;19:793-6.

15. Burns JE, Yao J, Chalhoub D, Chen JJ, Summers RM. A machine learning algorithm to estimate sarcopenia on abdominal CT. Acad Radiol 2020;27:311-20.

16. Graffy PM, Liu J, Pickhardt PJ, Burns JE, Yao J, Summers RM. Deep learning-based muscle segmentation and quantification at abdominal CT: application to a longitudinal adult screening cohort for sarcopenia assessment. Br J Radiol 2019;92:20190327.

17. Rossi F, Valdora F, Bignotti B, Torri L, Succio G, Tagliafico AS. Evaluation of body computed tomographydetermined sarcopenia in breast cancer patients and clinical outcomes: a systematic review. Cancer Treat Res Commun 2019;21:100154.

18. Engelke K, Museyko O, Wang L, Laredo JD. Quantitative analysis of skeletal muscle by computed tomography imaging-state of the art. J Orthop Translat 2018;15:91-103.

19. Sherk VD, Bemben MG, Palmer IJ, Bemben DA. Effects of filtering methods on muscle and fat cross-sectional area measurement by pQCT: a technical note. Physiol Meas 2011;32:N65-72.

20. Cesari M, Pahor M, Lauretani F, Zamboni V, Bandinelli S, Bernabei R, Guralnik JM, Ferrucci L. Skeletal muscle and mortality results from the InCHIANTI Study. J Gerontol A Biol Sci Med Sci 2009;64:377-84. 
21. Perkisas S, Baudry S, Bauer J, Beckwée D, Cock AD, Hobbelen H, Jager-Wittenaar H, Kasiukiewicz A, Landi F, Marco E, Merello A, Piotrowicz K, Sánchez E, SánchezRodríguez D, Scafoglieri A, Cruz-Jentoft A, Vandewoude M. Application of ultrasound for muscle assessment in sarcopenia: towards standardized measurements. European Geriatric Medicine 2018;9:739-57.

22. Hida T, Ando K, Kobayashi K, Ito K, Tsushima M, Kobayakawa T, Morozumi M, Tanaka S, Machino M, Ota K, Kanbara S, Ito S, Ishiguro N, Hasegawa Y, Imagama S. Ultrasound measurement of thigh muscle thickness for assessment of sarcopenia. Nagoya J Med Sci 2018;80:519-27.

23. Fischer D, Bonati U, Wattjes MP. Recent developments in muscle imaging of neuromuscular disorders. Curr Opin Neurol 2016;29:614-20.

24. Guerri S, Mercatelli D, Aparisi Gómez MP, et al. Quantitative imaging techniques for the assessment of osteoporosis and sarcopenia. Quant Imaging Med Surg 2018;8:60-85.

25. Messina C, Maffi G, Vitale JA, Ulivieri FM, Guglielmi G, Sconfienza LM. Diagnostic imaging of osteoporosis and sarcopenia: a narrative review. Quant Imaging Med Surg 2018;8:86-99.

26. Janssen I, Heymsfield SB, Ross R. Low relative skeletal muscle mass (sarcopenia) in older persons is associated with functional impairment and physical disability. J Am Geriatr Soc 2002;50:889-96.

27. Shalender Bhasin, Thomas G. Travison, Todd M. Manini, Sheena Patel, Karol M. Pencina, Roger A. Fielding, Jay M. Magaziner, Anne B. Newman, Douglas P. Kiel, Cyrus Cooper, Jack Guralnik, Jane Cauley, Hidenori Arai, Brian Clark, Francesco Landi, Laura Schaap, Suzette Pereira, Daniel Rooks, Jean Woo, Linda J. Woodhouse, Ellen Binder, Todd Brown, Michelle Shardell, Quian-Li Xue, Ralph B. D’Agostino, Denise Orwig, Greg Gorsicki, Rosaly Correa-De-Araujo, Peggy M. Cawthon. The position statements of the sarcopenia definition and outcomes consortium. Bethesda: Foundation for the National Institutes of Health, 2019.

28. Cawthon PM, Travison TG, Manini TM, Patel S, Pencina KM, Fielding RA, Magaziner JM, Newman AB, Brown T, Kiel DP, Cummings SR, Shardel M, Guralnik J, Woodhouse LJ, Pahor M, Binder E, D'Agostino RB, Xue QL, Orwoll E, Landi F, Orwig D, Schaap L, Latham N NK, Hirani V, Kwok T, Pereira S, Rooks D, Kashiwa M, Torres-Gonzalez M, Menetski JP, Correa-De-Araujo R, Bhasin S; Sarcopenia Definition and Outcomes Consortium Conference participants. Establishing the link between lean mass and grip strength cut-points with mobility disability and other health outcomes: proceedings of the Sarcopenia Definition and Outcomes Consortium Conference. J Gerontol A Biol Sci Med Sci 2020;75:1317-23.

29. Goodpaster BH, Thaete FL, Kelley DE. Composition of skeletal muscle evaluated with computed tomography. Ann N Y Acad Sci 2000;904:18-24.

30. Ross R. Advances in the application of imaging methods in applied and clinical physiology. Acta Diabetol 2003;40:S45-50.

31. Aubrey J, Esfandiari N, Baracos VE, Buteau FA, Frenette J, Putman CT, Mazurak VC. Measurement of skeletal muscle radiation attenuation and basis of its biological variation. Acta Physiol (Oxf) 2014;210:489-97.

32. Mitsiopoulos N, Baumgartner RN, Heymsfield SB, Lyons W, Gallagher D, Ross R. Cadaver validation of skeletal muscle measurement by magnetic resonance imaging and computerized tomography. J Appl Physiol (1985) 1998;85:115-22.

33. Mathur S, Rodrigues N, Mendes P, Rozenberg D, Singer LG. Computed tomography-derived thoracic muscle size as an indicator of sarcopenia in people with advanced lung disease. Cardiopulmonary Physical Therapy Journal 2017;28:99-105.

34. Dabiri S, Popuri K, Cespedes E, Caan B, Baracos V, Beg MF. Muscle Segmentation in axial computed tomography (CT) images at the lumbar (L3) and thoracic (T4) levels for body composition analysis. Comput Med Imaging Graph 2019;75:47-55.

35. Zwart AT, van der Hoorn A, van Ooijen PMA, Steenbakkers RJHM, de Bock GH, Halmos GB. CTmeasured skeletal muscle mass used to assess frailty in patients with head and neck cancer. J Cachexia Sarcopenia Muscle 2019;10:1060-9.

36. Nemec U, Heidinger B, Sokas C, Chu L, Eisenberg RL. Diagnosing sarcopenia on thoracic computed tomography: quantitative assessment of skeletal muscle mass in patients undergoing transcatheter aortic valve replacement. Acad Radiol 2017;24:1154-61.

37. Derstine BA, Holcombe SA, Goulson RL, Ross BE, Wang NC, Sullivan JA, Su GL, Wang SC. Quantifying sarcopenia reference values using lumbar and thoracic muscle areas in a healthy population. J Nutr Health Aging 2017;21:180-5.

38. Nattenmüller J, Wochner R, Muley T, et al. Prognostic Impact of CT-Quantified muscle and fat distribution before and after first-line-chemotherapy in lung cancer 
patients. PLoS One 2017;12:e0169136.

39. Erlandson MC, Lorbergs AL, Mathur S, Cheung AM. Muscle analysis using pQCT, DXA and MRI. Eur J Radiol 2016;85:1505-11.

40. Ismail C, Zabal J, Hernandez HJ, Woletz P, Manning H, Teixeira C, DiPietro L, Blackman MR, Harris-Love MO. Diagnostic ultrasound estimates of muscle mass and muscle quality discriminate between women with and without sarcopenia. Front Physiol 2015;6:302.

41. Stringer HJ, Wilson D. The role of ultrasound as a diagnostic tool for sarcopenia. J Frailty Aging 2018;7:258-61.

42. Reimers CD, Harder T, Saxe H. Age-related muscle atrophy does not affect all muscles and can partly be compensated by physical activity: an ultrasound study. J Neurol Sci 1998;159:60-6. Erratum in: J Neurol Sci 1999;162:211.

43. Sconfienza LM. Sarcopenia: ultrasound today, smartphones tomorrow? Eur Radiol 2019;29:1-2.

44. Goutallier D, Postel JM, Bernageau J, Lavau L, Voisin MC. Fatty muscle degeneration in cuff ruptures. Pre- and postoperative evaluation by CT scan. Clin Orthop Relat Res 1994;304:78-83.

45. Mercuri E, Talim B, Moghadaszadeh B, Petit N, Brockington M, Counsell S, Guicheney P, Muntoni F, Merlini L. Clinical and imaging findings in six cases of congenital muscular dystrophy with rigid spine syndrome linked to chromosome 1p (RSMD1). Neuromuscul Disord 2002;12:631-8.

46. Kalia V, Leung DG, Sneag DB, Del Grande F, Carrino JA. Advanced MRI techniques for muscle imaging. Semin Musculoskelet Radiol 2017;21:459-69.

47. Boutin RD, Yao L, Canter RJ, Lenchik L. Sarcopenia: current concepts and imaging implications. AJR Am J Roentgenol 2015;205:W255-66.

48. Duijnisveld BJ, Henseler JF, Reijnierse M, Fiocco M, Kan HE, Nelissen RG. Quantitative Dixon MRI sequences to relate muscle atrophy and fatty degeneration with range of motion and muscle force in brachial plexus injury. Magn Reson Imaging 2017;36:98-104.

49. Grimm A, Meyer H, Nickel MD, Nittka M, Raithel E, Chaudry O, Friedberger A, Uder M, Kemmler W, Engelke K, Quick HH. A comparison between 6-point Dixon MRI and MR spectroscopy to quantify muscle fat in the thigh of subjects with sarcopenia. J Frailty Aging 2019;8:21-6.

50. Triplett WT, Baligand C, Forbes SC, Willcocks RJ, Lott DJ, DeVos S, Pollaro J, Rooney WD, Sweeney HL, Bönnemann CG, Wang DJ, Vandenborne K, Walter GA. Chemical shift-based MRI to measure fat fractions in dystrophic skeletal muscle. Magn Reson Med 2014;72:8-19.

51. Nardo L, Karampinos DC, Lansdown DA, CarballidoGamio J, Lee S, Maroldi R, Ma CB, Link TM, Krug R. Quantitative assessment of fat infiltration in the rotator cuff muscles using water-fat MRI. J Magn Reson Imaging 2014;39:1178-85.

52. Karampinos DC, Baum T, Nardo L, Alizai H, Yu H, Carballido-Gamio J, Yap SP, Shimakawa A, Link TM, Majumdar S. Characterization of the regional distribution of skeletal muscle adipose tissue in type 2 diabetes using chemical shift-based water/fat separation. J Magn Reson Imaging 2012;35:899-907.

53. Pineda AR, Reeder SB, Wen Z, Pelc NJ. Cramér-Rao bounds for three-point decomposition of water and fat. Magn Reson Med 2005;54:625-35.

54. Guerini H, Omoumi P, Guichoux F, Vuillemin V, Morvan G, Zins M, Thevenin F, Drape JL. Fat suppression with Dixon techniques in musculoskeletal magnetic resonance imaging: a pictorial review. Semin Musculoskelet Radiol 2015;19:335-47.

55. Boesch C. Musculoskeletal spectroscopy. J Magn Reson Imaging 2007;25:321-38.

56. Edwards RH, Dawson MJ, Wilkie DR, Gordon RE, Shaw D. Clinical use of nuclear magnetic resonance in the investigation of myopathy. Lancet 1982;1:725-31.

57. Chance B, Eleff S, Bank W, Leigh JS Jr, Warnell R. 31P NMR studies of control of mitochondrial function in phosphofructokinase-deficient human skeletal muscle. Proc Natl Acad Sci U S A 1982;79:7714-8.

58. Park JH, Brown RL, Park CR, McCully K, Cohn M, Haselgrove J, Chance B. Functional pools of oxidative and glycolytic fibers in human muscle observed by $31 \mathrm{P}$ magnetic resonance spectroscopy during exercise. Proc Natl Acad Sci U S A 1987;84:8976-80.

59. Roth K, Weiner MW. Determination of cytosolic ADP and AMP concentrations and the free energy of ATP hydrolysis in human muscle and brain tissues with 31P NMR spectroscopy. Magn Reson Med 1991;22:505-11. Erratum in: Magn Reson Med 1995;33:282.

60. de Kerviler E, Leroy-Willig A, Jehenson P, Duboc D, Eymard B, Syrota A. Exercise-induced muscle modifications: study of healthy subjects and patients with metabolic myopathies with MR imaging and P-31 spectroscopy. Radiology 1991;181:259-64.

61. Kan HE, Klomp DW, Wohlgemuth M, van LoosbroekWagemans I, van Engelen BG, Padberg GW, Heerschap A. Only fat infiltrated muscles in resting lower leg of FSHD patients show disturbed energy metabolism. NMR Biomed 
2010;23:563-8.

62. Heier CR, Guerron AD, Korotcov A, Lin S, GordishDressman H, Fricke S, Sze RW, Hoffman EP, Wang P, Nagaraju K. Non-invasive MRI and spectroscopy of $\mathrm{mdx}$ mice reveal temporal changes in dystrophic muscle imaging and in energy deficits. PLoS One 2014;9:e112477.

63. Liu Y, Gu Y, Yu X. Assessing tissue metabolism by phosphorous-31 magnetic resonance spectroscopy and imaging: a methodology review. Quant Imaging Med Surg 2017;7:707-26.

64. Torriani M, Thomas BJ, Halpern EF, Jensen ME, Rosenthal DI, Palmer WE. Intramyocellular lipid quantification: repeatability with $1 \mathrm{H}$ MR spectroscopy. Radiology 2005;236:609-14.

65. Subhawong TK, Wang X, Machado AJ, Mammen AL, Christopher-Stine L, Barker PB, Carrino JA, Fayad LM. 1H Magnetic resonance spectroscopy findings in idiopathic inflammatory myopathies at $3 \mathrm{~T}$ : feasibility and first results. Invest Radiol 2013;48:509-16.

66. Fayad LM, Wang X, Salibi N, Barker PB, Jacobs MA, Machado AJ, Weber KL, Bluemke DA. A feasibility study of quantitative molecular characterization of musculoskeletal lesions by proton MR spectroscopy at $3 \mathrm{~T}$. AJR Am J Roentgenol 2010;195:W69-75.

67. Koh DM, Collins DJ. Diffusion-weighted MRI in the body: applications and challenges in oncology. AJR Am J Roentgenol 2007;188:1622-35.

68. Budzik JF, Balbi V, Verclytte S, Pansini V, Le Thuc V, Cotten A. Diffusion tensor imaging in musculoskeletal disorders. Radiographics 2014;34:E56-72.

69. White NS, McDonald C, Farid N, Kuperman J, Karow D, Schenker-Ahmed NM, Bartsch H, RakowPenner R, Holland D, Shabaik A, Bjørnerud A, Hope T, Hattangadi-Gluth J, Liss M, Parsons JK, Chen CC, Raman S, Margolis D, Reiter RE, Marks L, Kesari S, Mundt AJ, Kane CJ, Carter BS, Bradley WG, Dale AM. Diffusion-weighted imaging in cancer: physical foundations and applications of restriction spectrum imaging. Cancer Res 2014;74:4638-52.

70. Mayerhoefer ME, Karanikas G, Kletter K, Prosch H, Kiesewetter B, Skrabs C, Porpaczy E, Weber M, Knogler T, Sillaber C, Jaeger U, Simonitsch-Klupp I, Ubl P, Müllauer L, Dolak W, Lukas J, Raderer M. Evaluation of diffusion-weighted magnetic resonance imaging for followup and treatment response assessment of lymphoma: results of an 18F-FDG-PET/CT-controlled prospective study in 64 patients. Clin Cancer Res 2015;21:2506-13.

71. Giraudo C, Raderer M, Karanikas G, Weber M,
Kiesewetter B, Dolak W, Simonitsch-Klupp I, Mayerhoefer ME. 18F-fluorodeoxyglucose positron emission tomography/magnetic resonance in lymphoma: comparison with $18 \mathrm{~F}$-fluorodeoxyglucose positron emission tomography/computed tomography and with the addition of magnetic resonance diffusion-weighted imaging. Invest Radiol 2016;51:163-9.

72. Qi J, Olsen NJ, Price RR, Winston JA, Park JH. Diffusion-weighted imaging of inflammatory myopathies: polymyositis and dermatomyositis. J Magn Reson Imaging 2008;27:212-7.

73. Meyer HJ, Emmer A, Kornhuber M, Surov A. Associations between apparent diffusion coefficient and electromyography parameters in myositis-a preliminary study. Brain Behav 2018;8:e00958.

74. Surov A, Paul L, Meyer HJ, Schob S, Engelmann C, Wienke A. Apparent diffusion coefficient is a novel imaging biomarker of myopathic changes in liver cirrhosis. J Clin Med 2018;7:1-9.

75. McPherson JG, Smith AC, Duben DA, McMahon KL, Wasielewski M, Parrish TB, Elliott JM. Short- and long-term reproducibility of diffusion-weighted magnetic resonance imaging of lower extremity musculature in asymptomatic individuals and a comparison to individuals with spinal cord injury. BMC Musculoskelet Disord 2018;19:433.

76. Chilla GS, Tan CH, Xu C, Poh CL. Diffusion weighted magnetic resonance imaging and its recent trend-a survey. Quant Imaging Med Surg 2015;5:407-22.

77. Le Bihan D, Mangin JF, Poupon C, Clark CA, Pappata S, Molko N, Chabriat H. Diffusion tensor imaging: concepts and applications. J Magn Reson Imaging 2001;13:534-46.

78. Merboldt KD, Hanicke W, Frahm J. Self-diffusion NMR imaging using stimulated echoes. J Magn Reson (1969) 1985;64:479-86.

79. Taylor DG, Bushell MC. The spatial mapping of translational diffusion coefficients by the NMR imaging technique. Phys Med Biol 1985;30:345-9.

80. Sinha U, Csapo R, Malis V, Xue Y, Sinha S. Agerelated differences in diffusion tensor indices and fiber architecture in the medial and lateral gastrocnemius. J Magn Reson Imaging 2015;41:941-53.

81. Heemskerk AM, Sinha TK, Wilson KJ, Ding Z, Damon BM. Quantitative assessment of DTI-based muscle fiber tracking and optimal tracking parameters. Magn Reson Med 2009;61:467-72.

82. Damon BM, Buck AK, Ding Z. Diffusion-tensor MRI based skeletal muscle fiber tracking. Imaging Med 2011;3:675-87. 
83. Giraudo C, Motyka S, Weber M, Feiweier T, Trattnig S, Bogner W. Diffusion tensor imaging of healthy skeletal muscles: a comparison between $7 \mathrm{~T}$ and $3 \mathrm{~T}$. Invest Radiol 2019;54:48-54.

84. Giraudo C, Motyka S, Weber M, Karner M, Resinger C, Feiweier T, Trattnig S, Bogner W. Normalized STEAM-based diffusion tensor imaging provides a robust assessment of muscle tears in football players: preliminary results of a new approach to evaluate muscle injuries. Eur Radiol 2018;28:2882-9.

85. Sigmund EE, Sui D, Ukpebor O, Baete S, Fieremans E, Babb JS, Mechlin M, Liu K, Kwon J, McGorty K, Hodnett PA, Bencardino J. Stimulated echo diffusion tensor imaging and SPAIR T2-weighted imaging in chronic exertional compartment syndrome of the lower leg muscles. J Magn Reson Imaging 2013;38:1073-82.

86. Froeling M, Oudeman J, Strijkers GJ, Maas M, Drost MR, Nicolay K, Nederveen AJ. Muscle changes detected with diffusion-tensor imaging after long-distance running. Radiology 2015;274:548-62.

87. Esposito A, Campana L, Palmisano A, De Cobelli F, Canu T, Santarella F, Colantoni C, Monno A, Vezzoli M, Pezzetti G, Manfredi AA, Rovere-Querini P, Del Maschio A. Magnetic resonance imaging at $7 \mathrm{~T}$ reveals common events in age-related sarcopenia and in the homeostatic response to muscle sterile injury. PLoS One 2013;8:e59308.

88. Galbán CJ, Maderwald S, Stock F, Ladd ME. Age-related changes in skeletal muscle as detected by diffusion tensor magnetic resonance imaging. J Gerontol A Biol Sci Med Sci 2007;62:453-8.

89. Ponrartana S, Ramos-Platt L, Wren TA, Hu HH, Perkins TG, Chia JM, Gilsanz V. Effectiveness of diffusion tensor imaging in assessing disease severity in Duchenne muscular dystrophy: preliminary study. Pediatr Radiol 2015;45:582-9.

90. Oudeman J, Nederveen AJ, Strijkers GJ, Maas M, Luijten PR, Froeling M. Techniques and applications of skeletal muscle diffusion tensor imaging: a review. J Magn Reson Imaging 2016;43:773-88.

91. Noehren B, Andersen A, Feiweier T, Damon B, Hardy P. Comparison of twice refocused spin echo versus stimulated echo diffusion tensor imaging for tracking muscle fibers. J Magn Reson Imaging 2015;41:624-32.

92. Chang LC, Jones DK, Pierpaoli C. RESTORE: robust estimation of tensors by outlier rejection. Magn Reson Med 2005;53:1088-95.

93. Chang LC, Walker L, Pierpaoli C. Informed RESTORE: a method for robust estimation of diffusion tensor from low redundancy datasets in the presence of physiological noise artifacts. Magn Reson Med 2012;68:1654-63.

94. Collier Q, Veraart J, Jeurissen B, den Dekker AJ, Sijbers J. Iterative reweighted linear least squares for accurate, fast, and robust estimation of diffusion magnetic resonance parameters. Magn Reson Med 2015;73:2174-84.

95. Giraudo C, Motyka S, Weber M, Resinger C, Thorsten F, Traxler H, Trattnig S, Bogner W. Weighted mean of signal intensity for unbiased fiber tracking of skeletal muscles: development of a new method and comparison with other correction techniques. Invest Radiol 2017;52:488-97.

96. Marty B, Coppa B, Carlier PG. Monitoring skeletal muscle chronic fatty degenerations with fast T1-mapping. Eur Radiol 2018;28:4662-8.

97. Marty B, Carlier PG. Physiological and pathological skeletal muscle T1 changes quantified using a fast inversion-recovery radial NMR imaging sequence. Sci Rep 2019;9:6852.

98. Azzabou N, Hogrel JY, Carlier PG. NMR based biomarkers to study age-related changes in the human quadriceps. Exp Gerontol 2015;70:54-60.

99. Arpan I, Forbes SC, Lott DJ, Senesac CR, Daniels MJ, Triplett WT, Deol JK, Sweeney HL, Walter GA, Vandenborne K. T2 mapping provides multiple approaches for the characterization of muscle involvement in neuromuscular diseases: a crosssectional study of lower leg muscles in 5-15-year-old boys with Duchenne muscular dystrophy. NMR Biomed 2013;26:320-8.

100.Ma D, Gulani V, Seiberlich N, Liu K, Sunshine JL, Duerk JL, Griswold MA. Magnetic resonance fingerprinting. Nature 2013;495:187-92.
Cite this article as: Giraudo C, Cavaliere A, Lupi A, Guglielmi G, Quaia E. Established paths and new avenues: a review of the main radiological techniques for investigating sarcopenia. Quant Imaging Med Surg 2020;10(8):1602-1613. doi: 10.21037/ qims.2019.12.15 